\title{
Berberine promotes glucagon-like peptide-1 (7-36) amide secretion in streptozotocin-induced diabetic rats
}

\author{
Shou-Si Lu, Yun-Li Yu, Hao-Jie Zhu', Xiao-Dong Liu, Li Liu, Yao-Wu Liu, Ping Wang, Lin Xie \\ and Guang-Ji Wang \\ Key Lab of Drug Metabolism and Pharmacokinetics, China Pharmaceutical University, Nanjing 210009, People's Republic of China \\ ${ }^{1}$ Department of Pharmaceutical and Biomedical Science, Medical University of South Carolina, Charleston, South Carolina 29425, USA \\ (Correspondence should be addressed to X-D Liu; Email: xdliu@cpu.edu.cn)
}

\begin{abstract}
Berberine (BBR), a hypoglycemic agent, has shown beneficial metabolic effects for anti-diabetes, but its precise mechanism was unclear. Glucagon-like peptide-1 (GLP-1) is considered to be an important incretin that can decrease hyperglycemia in the gastrointestinal tract after meals. The aim of this study was to investigate whether BBR exerts its anti-diabetic effects via modulating GCG secretion. Diabeteslike rats induced by streptozotocin received BBR $(120 \mathrm{mg} / \mathrm{kg}$ per day, i.g) for 5 weeks. Two hours following the last dose, the rats were anaesthetized and received $2.5 \mathrm{~g} / \mathrm{kg}$ glucose by gavage. At 15-minute and 30-minute after glucose load, blood samples, pancreas, and intestines were obtained to measure insulin and GCG using ELISA kit. The number of L
\end{abstract}

cells in the ileum and $\beta$-cells in the pancreas were identified using immunohistology. The expression of proglucagon mRNA in the ileum was measured by RT-PCR. The results indicated that BBR treatment significantly increased GCG levels in plasma and intestine $(P<0 \cdot 05)$ accompanied with the increase of proglucagon mRNA expression and the number of L-cell compared with the controls $(P<0 \cdot 05)$. Furthermore, BBR increased insulin levels in plasma and pancreas as well as $\beta$-cell number in pancreas. The data support the hypothesis that the anti-diabetic effects of BBR may partly result from enhancing GCG secretion.

Journal of Endocrinology (2009) 200, 159-165

\section{Introduction}

Berberine (BBR, $\left[\mathrm{C}_{20} \mathrm{H}_{18} \mathrm{NO}_{4}\right]^{+}$) is an isoquinoline alkaloid originally isolated from coptidis rhizoma. In China, BBR has been extensively used as a non-prescription drug to treat bacteria-caused diarrhea for many years (Zhang et al. 1989). Recently, accumulating evidence has demonstrated that BBR may be used as an anti-diabetes agent (Pan et al. 2003, Tang et al. 2006, Zhou et al. 2008). BBR can modulate glucose and lipid metabolism, stimulate insulin secretion, and improve diabetic symptoms (Kong et al. 2004, Leng et al. 2004). Many in vitro studies show that $\mathrm{BBR}$ may promote insulin release thereby acting as a glucokinase activator or insulin sensitizing and insulinotropic agent (Ko et al. 2005, Wang et al. 2007). BBR can also enhance glucose uptake and increase GLUT-4 transporter activity in muscle and reduce lipid accumulation in adipocytes via stimulating AMPK activity (Cheng et al. 2006). However, the BBR concentrations used in these studies were 1-100 $\mu \mathrm{M}$, which can not be obtained in vivo. BBR absorption is very poor in the gut with the absolute bioavailability less than $10 \%$. Our previous study showed that peak concentration of BBR in plasma was only $14 \cdot 9$ $17 \cdot 8 \mathrm{nM}$ following oral administration in rats at a dose of $245 \mathrm{mg} / \mathrm{kg}$ (Lu et al. 2006, Yu et al. 2007). These observations were not consistent with the idea that BBR acted directly on studied cell-lines in vitro (Cheng et al. 2006, Turner et al. 2008). The results obtained in vitro can not explain the antidiabetes mechanism of BBR in vivo, which indicated that other mechanisms involved in the anti-diabetic effect of BBR in the gastrointestinal tract existed.

It is well known that the intestine play is an important role in the regulation of endocrine pancreatic secretion. The intestinal products of the proglucagon gene, glucagon-like peptide-1 (GLP-1), has been shown to contribute significantly to the overall insulin response to oral glucose and is now considered to be one of the important incretins in the gastrointestinal tract after meals (Doyle \& Egan 2007). The peptide is encoded by the proglucagon gene, mainly produced in enteroendocrine $\mathrm{L}$ cells of the gut, and secreted into the blood stream in response to nutrient ingestion (Meier \& Nauck 2005). Importantly, GCG is essential in the regulation of glucose homeostasis, insulin secretion, and $\beta$-cell proliferation and differentiation in the pancreas (Holst \& Gromada 2004). GCG may also inhibit glucagon secretion, gastric emptying, and appetite (Turton et al. 1996, Holst et al. 2008). Many factors including glucose load, corn oil, and non-digestible carbohydrates oligofructose may stimulate GCG secretion (Iritani et al. 1999, Cani et al. 2007). Atropine and pirenzepine may block corn oil-induced GCG 
secretion indicated that $\mathrm{M}_{2}$-receptor may be involved in GCG secretion (Anini et al. 2002). Therefore, the aim of this study was to investigate whether BBR modulates GCG secretion and produces anti-diabetic effects in diabetic rats induced by streptozotocin.

\section{Materials and Methods}

\section{Animal and materials}

Male Sprague-Dawley rats (180-220 g) were purchased from Sino-British Sippr/BK Lab Animal Ltd (Shanghai, China) and housed under controlled conditions of humidity $(50 \% \pm 5 \%)$ and temperature $\left(23 \pm 1{ }^{\circ} \mathrm{C}\right)$ with a $12 \mathrm{~h}$ light: $12 \mathrm{~h}$ darkness cycle. Food and water were given ad libitum for the study. All animal experiments were performed under a license granted by Jiangsu Science and Technology Office of China, with the approval from Animal Ethics Committee of China Pharmaceutical University. Every effort was made to minimize stress to the animals. BBR (purity: 98\%) was purchased from Nanjing Qingze Pharmaceutical Technology Ltd, Co., (Nanjing, China).

\section{Experimental procedures}

Following an acclimation period of 3 days, the rats were fasted overnight and diabetes was induced by i.p. injection of streptozotocin $(65 \mathrm{mg} / \mathrm{kg}$, Sigma, Stzid) dissolved in $0 \cdot 1 \mathrm{M}$ sodium citrate buffer at $\mathrm{pH} 4 \cdot 5$. Following injection, animals were returned to their cages for the remaining study. Agematched control rats received only the citrate buffer.

Development of diabetes was confirmed by fasting blood glucose (FBG) analysis using a reagent kit (Jian-cheng Biotech Co., Nanjing, China). Rats with a FBG level higher than $11.1 \mathrm{mM}$ on the third day following i.p streptozotocin were considered to be diabetic rats and included in the study. The streptozotocin-induced hyperglycemic state was considered as the type 1 DM model (Liu et al. 2008a,b).

On the fourth day following injection of streptozotocin, the diabetic rats were randomly divided into two groups. Group I served as the diabetic control (Stzid-CT, $n=11$ ) and only received the vehicle. Group II (Stzid-BBR, $n=11$ ) was orally dosed with BBR $(120 \mathrm{mg} / \mathrm{kg})$ once a day for 5 weeks. The age-matched rats received only the vehicle serving as normal control. Food intake, FBG, and body weight were measured once a week. Following 5 -week treatment, the rats were subjected to analysis of GCG and insulin levels in plasma and tissue.

\section{Blood and tissue samples}

On days $7,14,21,28$, and 35 of the treatment, rats fasted for $8 \mathrm{~h}$. Under anesthesia with ether, blood samples were collected via the ocular vein in EDTA tubes. Plasma was obtained by centrifugation and stored at $-20{ }^{\circ} \mathrm{C}$. The FBG levels were measured using the reagent kit. On day 35, at $2 \mathrm{~h}$ after the last treatment, the rats were anaesthetized by i.p sodium pentobarbital $(60 \mathrm{mg} / \mathrm{kg})$ and received $2.5 \mathrm{~g} / \mathrm{kg}$ of glucose by gavage, then the abdominal cavity was opened and canula was inserted in portal vein. At $15 \mathrm{~min}$ and $30 \mathrm{~min}$ following glucose load, portal blood samples were collected in EDTA tubes containing dipeptidyl peptidase IV inhibitor $(10 \mu \mathrm{l} / \mathrm{ml}$, ADL Research, Santa Barbara, CA, USA) via the portal vein. Plasma samples were obtained and stored at $-80{ }^{\circ} \mathrm{C}$ for assessment of GLP-1(7-36) amide and insulin.

Rats were then killed immediately. Pancreas, segments of distal ileum $(4 \mathrm{~cm}$ of intestine taken above the junction with the caecum), and proximal colon ( $4 \mathrm{~cm}$ of intestine below the junction with the caecum) were excised, washed with ice-cold saline, weighed, and stored at $-80^{\circ} \mathrm{C}$ for assessment of insulin or GLP-1(7-36) amide. Parts of tissues were used for immunohistochemistry or RT-PCR analysis of proglucagon mRNA.

\section{Measurement of GLP-1(7-36) amide in plasma and intestinal tissue}

GCG (7-36) amide was measured using an ELISA kit (Linco Research, St Charles, MO, USA) specific for GCG (7-36) amide without cross-reactivity towards GCG (9-36) amide, GLP-2 and glucagon. GLP-1(7-36) amide was extracted from ileum and colon. Tissue samples were homogenized at $4{ }^{\circ} \mathrm{C}$ using ethanol/acid $(5: 1 \mathrm{v} / \mathrm{v})$ solution $(5 \mathrm{ml} / \mathrm{g}$ tissue $)$ and kept for $24 \mathrm{~h}$ at $4{ }^{\circ} \mathrm{C}$. After centrifugation, the supernatant was collected. GLP-1(7-36) amide levels in plasma and intestine were measured using an ELISA kit according to its manufacturer's protocol.

Measurement of insulin in plasma and pancreatic insulin content The insulin level in plasma and pancreas was assessed using an ELISA kit (ADL Research). Pancreas was weighed and homogenized at $4{ }^{\circ} \mathrm{C}$ in ethanol/acid $(\mathrm{HCl} 0 \cdot 15 \mathrm{mM}$, ethanol $75 \%)$ solution and kept at $4{ }^{\circ} \mathrm{C}$ overnight. After centrifugation, the supernatant was collected for insulin assay.

\section{Immunohistochemistry}

Tissues were fixed overnight in 4\% formaldehyde in PBS and mounted in paraffin. Sections ( $4 \mu \mathrm{m}$ thickness) were then incubated with hydrogen peroxide for $10 \mathrm{~min}$ at room temperature to block the endogenous peroxidase activity. The paraffin sections were immunostained by a rabbit antiGCG antibody (Phoenix Pharmaceuticals, St Joseph, MO, USA. 1:500) for ileum and a human anti-insulin antibody for pancreas, combined with a horse radish peroxidase (HRP) detection system. Finally, the peroxidase activity was revealed by immersion in a solution of $0.05 \% 3,3^{\prime}$ diaminobenzidine hydrochloride. The number of immune positive cells in a section was counted in two non-serial immunostained sections, using a light microscope (final magnification $400 \times$ ), by an investigator blind to the experimental group. 
For ileum tissue, mucosa area on the same material was manually delineated by the investigator and measured by a semiautomatic image analyzer. Results are expressed as the number of $\mathrm{L}$ cells per mucosal area (number $/ \mathrm{mm}^{2}$ ).

Pancreatic tissue was measured in three different sections per animal and $\beta$-cell volume density was estimated by calculating the proportion of cells immunoreactive for insulin per sectional area of total pancreas. The $\beta$-cell volume density corresponds to the ratio of $\beta$ cell area to pancreatic parenchymal area. The $\beta$-cell mass was calculated by multiplying the $\beta$-cell volume density by the weight of the pancreas (Cani et al. 2005).

\section{Proglucagon $m R N A$ : reverse transcriptase-PCRs (RT-PCR)}

Total RNA was isolated from the ileum utilizing Trizol reagent (Invitrogen Co) following the company's instruction. The purity of isolated RNA was determined using u.v. absorption at 260 and $280 \mathrm{~nm}$. The cDNA was synthesized from $2 \mu \mathrm{g}$ of total RNA using oligo (dT) 15 and M-MLV reverse transcriptase. PCR was performed on Gene Amp PCR System 9600. Primers used for the amplification of the cDNAs of interest were: for proglucagon gene (473 bp), forward $5^{\prime}$-GTAATGCTGGTACAAGGCAG- $3^{\prime}$ and reverse 5'-TTGATGAAGTCTCTGGTGGCA-3', for glyceraldehyde-phosphate dehydrogenase (GAPDH, $251 \mathrm{bp}$ ): forward $5^{\prime}$-CCATGTTCGTCATGGGTGTGAACCA- $3^{\prime}$ and reverse $5^{\prime}$-GCCAGTAGAGGCAGGGATGATGTTC- $3^{\prime}$ (Sheng-Xing Sci-Tech Co., Nanjing China). After denaturation at $95^{\circ} \mathrm{C}$ for $5 \mathrm{~min}$, the amplification was obtained by 30 cycles of $94^{\circ} \mathrm{C}$ for $30 \mathrm{~s}, 60^{\circ} \mathrm{C}$ for $30 \mathrm{~s}$, and $72{ }^{\circ} \mathrm{C}$ for $1 \mathrm{~min}$ each. A final extension step at $72^{\circ} \mathrm{C}$ for 5 min was employed. PCR products were subjected to electrophoresis on $2 \%$ agarose gel and visualized by ethidium bromide staining. Densitometric quantification was recorded using gel image analysis system 3.3 (Jiangsu Jeda ScienceTechnology Co., Ltd, Nanjing, China). To normalize data, the ratio between the densitometric quantification proglucagon gene and GAPDH gene was calculated by using the software Quantity One (Bio-Rad Labs).

\section{Statistical analysis}

Results were expressed as mean \pm s.E.M. The differences among groups were determined by one way ANOVA following Student-Newman-Keuls multiple comparison post hoc test. Differences were considered significant with $P<0 \cdot 05$.

\section{Results}

Modulation of plasma glucose, food intake, and body weight by $B B R$

Compared to the normal rats, FBG levels in diabetic rats significantly increased, accompanied by food intake higher and lower weight. BBR treatment significantly decreased plasma glucose $(P<0 \cdot 01$, Fig. $1 \mathrm{~A})$ and food intake
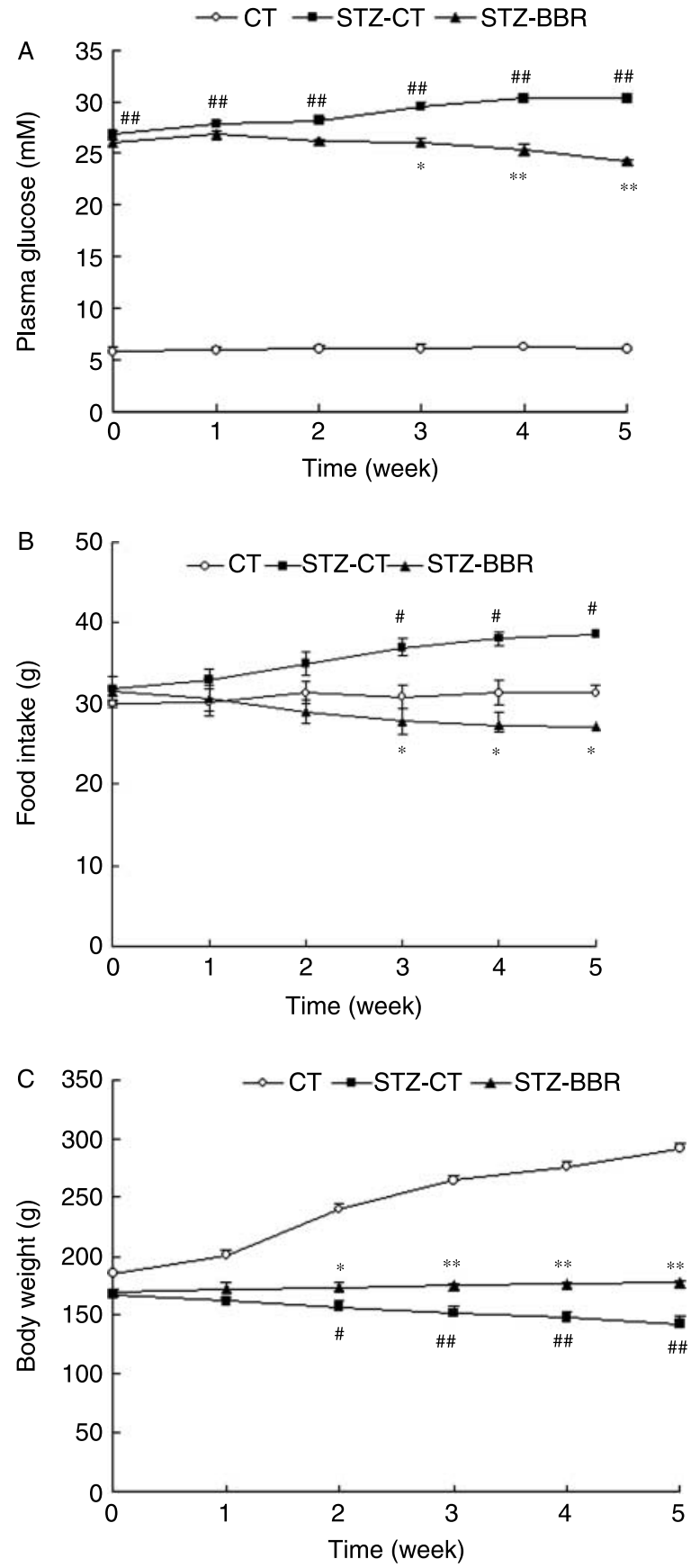

Figure 1 (A) Effect of berberine on the plasma glucose, (B) food intake, $(\mathrm{C})$ and body weight in streptozotocin induced diabetic rats during 5-week treatment. The rats were fasted for $8 \mathrm{~h}$. At $2 \mathrm{~h}$ after oral administration of berberine (Stzid-BBR $120 \mathrm{mg} / \mathrm{kg}$ ) or vehicle (CT and Stzid-CT), the rats were anaesthetized with ether to obtain blood samples. Blood glucose, food intake, and body weight were measured once a week, time (wk) indicated week after beginning of the treatment. Each data are mean \pm s.E.M. $(n=7) .{ }^{*} P<0 \cdot 05, * *$ $P<0 \cdot 01$ versus diabetes. ${ }^{\#} P<0.01$ versus control. 
$(P<0 \cdot 05$, Fig. 1B), and improved body weight $(P<0 \cdot 01$, Fig. 1C). The results further verified the anti-diabetic effects of BBR.

\section{Improvement of insulin level in plasma and pancreas by BBR}

Insulin levels in plasma and pancreas stimulated by oral glucose load were measured at $2 \mathrm{~h}$ after last treatment. StzidCT rats had significantly lower insulin levels in both plasma and pancreas, while BBR-treated rats had significantly greater insulin levels than Stzid-CT rats $(P<0 \cdot 05$, Fig. 2A and B).

In order to further investigate whether the lower insulin levels resulted from $\beta$-cell functionality, the number of $\beta$-cells was measured using immunohistochemistry. The number of $\beta$-cells in Stzid-CT rats was significantly lower than that in $\mathrm{CT}$ rats, and BBR treatment significantly increased the $\beta$-cell number of diabetic rats induced by Stzid, which was $4 \cdot 6$ times of Stzid-CT rats (Fig. 2C). The greater $\beta$-cell number was in parallel with higher insulin levels in plasma and pancreas. The data indicated BBR treatment may improve proliferation of $\beta$-cell in pancreas and enhance insulin secretion.

Effects of BBR on GLP-1(7-36) amide contents in the portal vein and intestines of Stzid - induced diabetic rats

Stzid-treated rats had significantly greater portal GLP-1(736) amide levels than CT rats (Fig. 3A): the level doubled in Stzid-CT as compared with normal rats. Furthermore, StzidBBR rats exhibited even greater portal GLP-1(7-36) amide levels, reaching three times that of $\mathrm{CT}$ rats. These results confirmed that BBR treatment increased plasma portal GLP1(7-36) amide. In the ileum, Stzid-CT displayed a significant decrease of GLP-1(7-36) amide concentration, BBR treatment significantly attenuated the decrease of GCG level induced by Stzid. In the colon, the lower GLP-1(7-36) amide level was only observed at $15 \mathrm{~min}$ following oral glucose load in Stzid-CT rats. BBR treatment reversed GLP-1(7-36) amide decrease induced by Stzid. But at $30 \mathrm{~min}$ following oral glucose load, GLP-1(7-36) amide level was affected by neither Stzid nor BBR treatment.

Effects of BBR on the expression of proglucagon $m R N A$ levels and L-cell number in ileum in Stzid - induced diabetic rats

Stzid-CT rats showed a slightly higher expression of proglucagon mRNA in the ileum segment than CT rats (Fig. 4). However, BBR-treated rats had a significantly greater expression of proglucagon mRNA $(P<0 \cdot 05$, Fig. 4B), which was double that of Stzid-CT rats.

The L cells were found in the micro-villi of the intestinal lumen. Slightly higher numbers of GLP-1-positive L cells were also found in the ileum of Stzid-CT rats. BBR-treated rats had even greater numbers of GCG positive L cells, almost twice those of normal rats, although no statistical difference was found (Fig. 4C).

\section{Discussion}

The main finding of the present study is that BBR treatment significantly increased GLP-1(7-36) amide levels in blood, ileum, and colon in diabetic rats induced by Stzid,
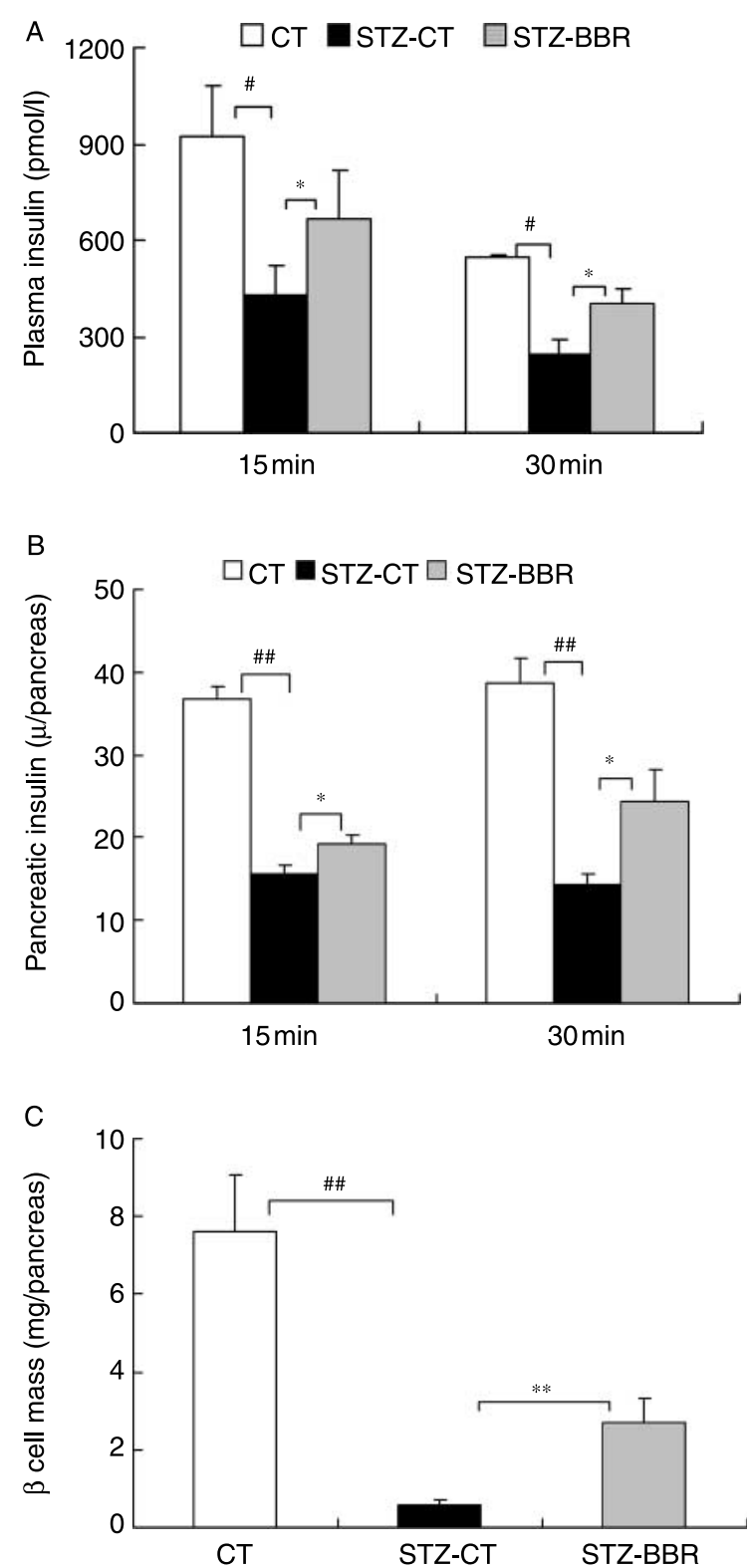

Figure 2 (A) Effect of berberine on insulin level in portal plasma (B) pancreas, and (C) $\beta$ cell number in pancreas of rats after 5 -week treatment. The rats were fasted for $8 \mathrm{~h}$. At $2 \mathrm{~h}$ after oral administration of berberine (Stzid-BBR $120 \mathrm{mg} / \mathrm{kg}$ ) or vehicle (CT and Stzid-CT), the rats were anaesthetized and received $2.5 \mathrm{~g} / \mathrm{kg}$ glucose by gavage. At 15 -minute and 30-minute following glucose load, blood samples, and pancreas were obtained to measure insulin levels and $\beta$-cell number in pancreas respectively. Data are mean \pm s.E.M. $(n=7) .{ }^{*} P<0 \cdot 05,{ }^{* *} P<0 \cdot 01$ versus diabetes.

$\# P<0 \cdot 01$ versus controls. 
accompanied by an increase of insulin in plasma and pancreatic tissue. Furthermore, it was found that BBR treatment may significantly increase proglucagon mRNA expression and the number of $\mathrm{L}$ cells in ileum.
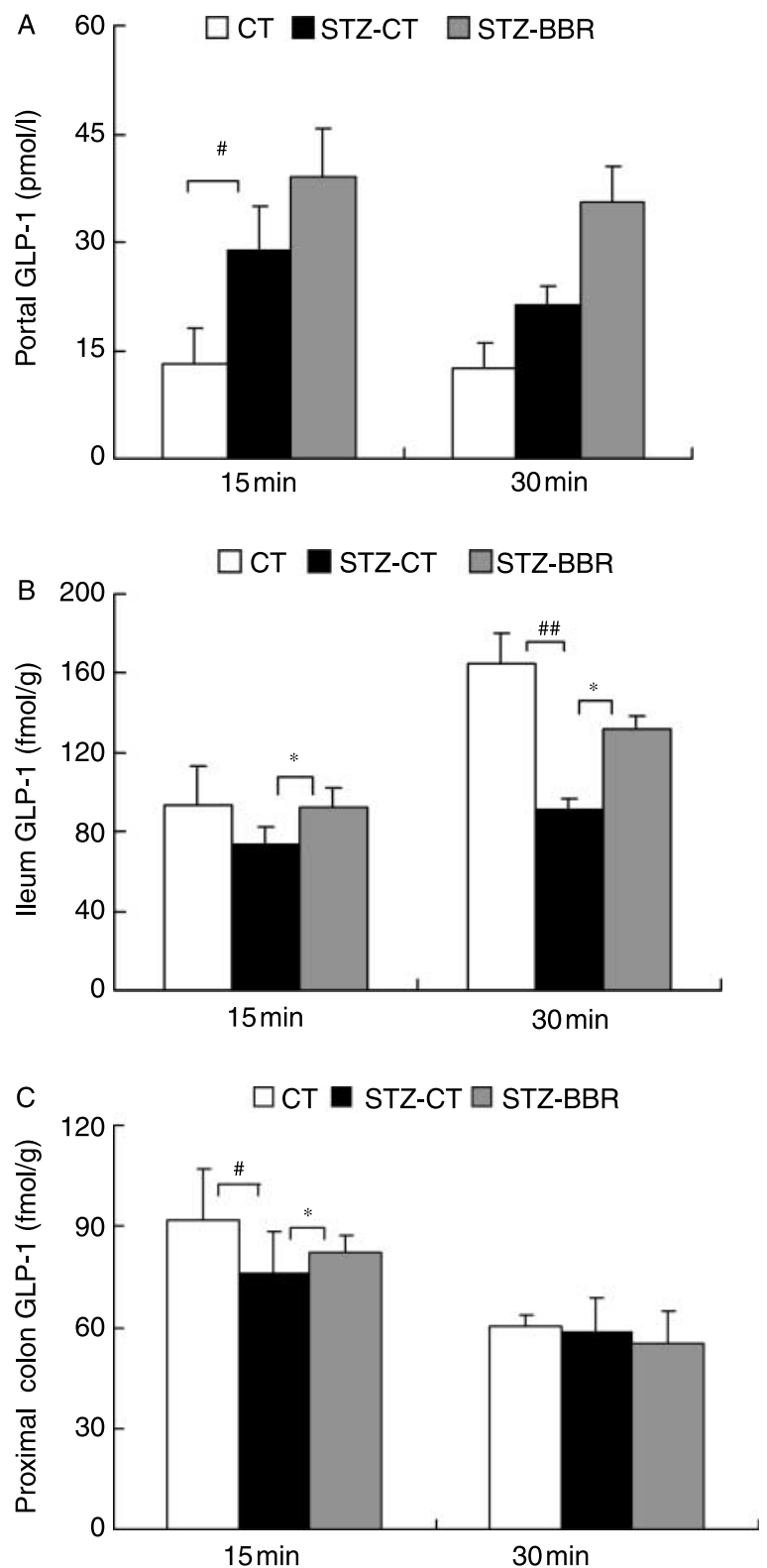

Figure 3 (A) Effect of berberine on the levels of GLP-1(7-36) amide in the portal vein, (B) ileum and (C) colon of rats after 5-week treatment. The rats were fasted for $8 \mathrm{~h}$, at $2 \mathrm{~h}$ after oral administration of berberine (Stzid-BBR $120 \mathrm{mg} / \mathrm{kg}$ ) or vehicle (CT and Stzid-CT), anaesthetized and received $2.5 \mathrm{~g} / \mathrm{kg}$ glucose by gavage. At 15-minute and 30-minute following glucose load, GCG levels were determined in blood and intestine tissue. Data presented as mean \pm S.E.M. $(n=7) . * P<0.05$ versus diabetes, ${ }^{\sharp} P<0.05$ versus controls.
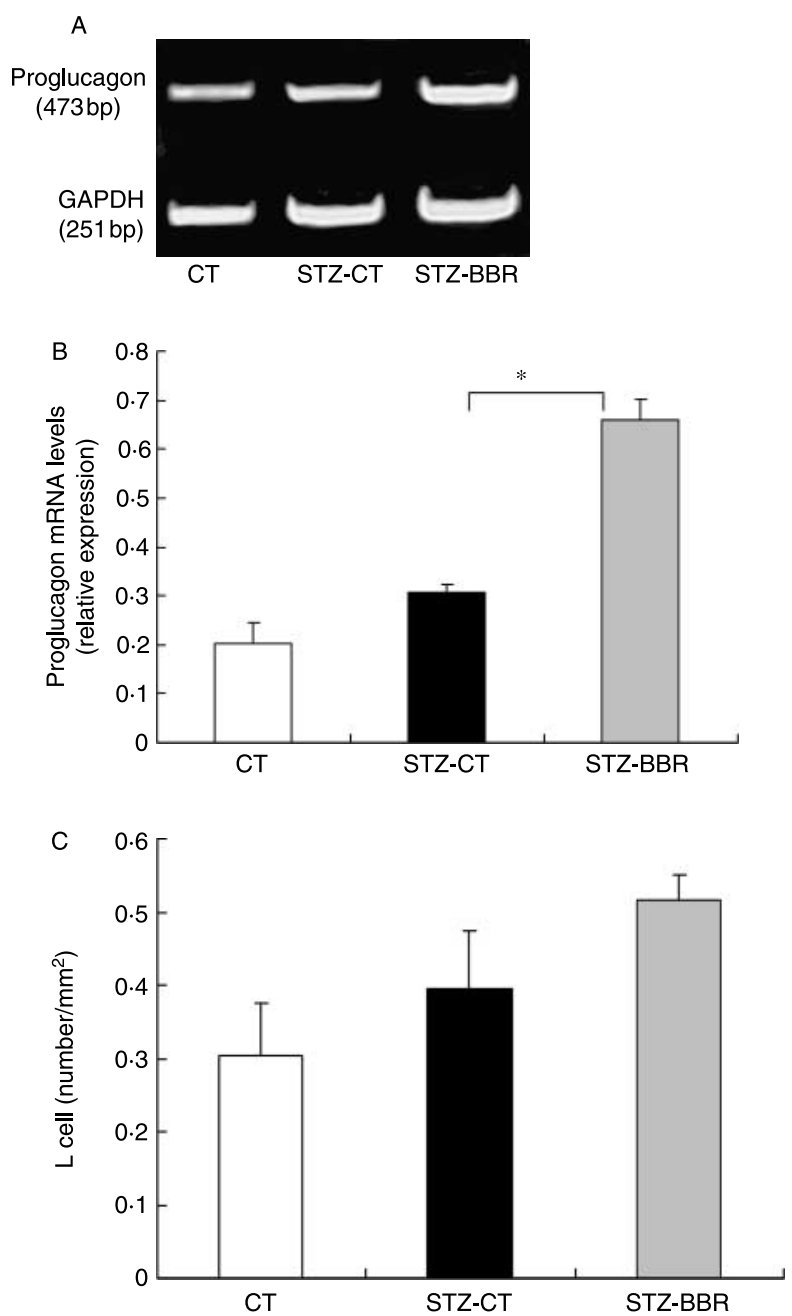

Figure $4(\mathrm{~A}, \mathrm{~B})$ Effect of berberine on the levels of proglucagon mRNA and (C) L-cell number in the ileum. The rats were fasted for $8 \mathrm{~h}$, at $2 \mathrm{~h}$ after oral administration of berberine (Stzid-BBR $120 \mathrm{mg} / \mathrm{kg}$ ) or vehicle (CT and Stzid-CT), anaesthetized and received $2.5 \mathrm{~g} / \mathrm{kg}$ glucose by gavage. At 15 -minute following glucose load, proglucagon mRNA expression levels and L-cell numbers in the ileum were determined by RT-PCR and immunohistology respectively. Data are mean \pm S.E.M. $(n=4) .{ }^{*} P<0 \cdot 05$ versus diabetes, ${ }^{\sharp} P<0.05$ versus controls.

GLP-1(7-36) amide was known to improve glucose homostasis by modulating insulin secretion (Drucker 2003). Our results showed that BBR may ameliorate blood glucose and body weight, and reduce food intake, which was consistent with other reports (Leng et al. 2004, Yin et al. 2007). Our data also showed some correlations between anti-hyperglycemia effect, insulin levels in plasma and pancreas, and GCG levels. This indicated that BBR increased insulin levels and regulated glucose homeostasis partly via enhancing GCG release.

BBR improved the insulin level in the plasma and tissue of diabetic rats. It was well-known that GLP-1 was one of the 
most potent factors for the enhancement of insulin secretion, and there were a few papers suggesting that GCG may increase insulin secretion by improving $\beta$-cell function with $\mathrm{EC}_{50}$ at about $10 \mathrm{pM}$ (Schmidtler et al. 1991, Fehmann et al. 1995). Our study showed that BBR treatment may increase GLP-1(7-36) amide release in plasma and intestine, the concentration of GCG in portal vein blood was about $30 \mathrm{pM}$, this suggested that $\mathrm{BBR}$ may improve $\beta$-cell function and tissue insulin via enhancing GCG release. Furthermore, the plasma GCG concentrations were in parallel to changes in insulin concentration, which suggested that it was possible that BBR promoted GCG release in the gut and the released GCG increased insulin secretion and improved function of $\beta$-cell in pancreas. Some reports showed that BBR may promote insulin release acting as a glucokinase activator or insulin sensitizing and insulinotropic agent (Pan et al. 2002, Wang et al. 2007), or stimulate glucose uptake via the MAPK pathway (Cheng et al. 2006), but BBR concentrations used in the in vitro study were impossible to attain in vivo. Our results indicated that BBR may directly act on mucosal cells and increase GCG secretion, followed by increasing function of $\beta$ cell in pancreas and increasing insulin level, which may be one of the mechanisms of BBR showing anti-diabetic effect.

It was reported that GCG can suppress food intake. One of the possibilities was that peripherally released GCG may directly act on the brain, because circulating GCG can enter brain areas (subfornical organ, area postrema) and participate in the regulation of the satiation effect and a reduction in appetite (Orskov et al. 1996, Verdich et al. 2001). Central administration of GCG inhibited food intake in rodents (Turton et al. 1996). Moreover, GCG may cause inhibitory effects on gastrointestinal secretion and motility (Ritzel et al. 1997). Intriguingly, we confirmed that BBR could lower food intake in rats under diabetic condition (Fig. 1B). Thus, the role for $\mathrm{BBR}$ on food intake suppression may be partly due to the action of GLP-1.

It was intriguing to assess the effects of $\mathrm{BBR}$ on promoting GCG secretion. Based on the data presented here, higher GCG contents were also found in portal vein of Stzid-CT rats, similar reports were found in Cani et al. (2005), but lower GCG contents were found in the intestinal tissues of Stzid-CT rats, the underlying causes were not fully understood. Five-week BBR treatment significantly increased GCG Level in plasma and tissues. The proglucagon gene, encodes the incretin hormone GLP-1, produced in the intestinal endocrine L cells (Yi et al. 2008). Intriguingly, the mRNA relative expression levels of proglucagon, the precursor of GLP-1, were highly expressed in ileum under BBR-treated-diabetic rats compared with diabetic rats. Furthermore, the immunohistology results of L cell, secreting GCG in intestine, had also shown that the treatment significantly increased the number of L-cell in comparison with Stzid-CT rats.

Other mechanisms may be involved in BBR promotion of GCG secretion. Previous research in our laboratory and other papers showed low in BBR concentrations in plasma due to poor absorption from the gastrointestinal tract (Pan et al. 2002, Lu et al. 2006). But higher BBR levels in gut may regulate gut microflora and inhibit $\alpha$-glucosidase activity (Pan et al. 2003). BBR may act as an $\boldsymbol{\alpha}$-glucosidase inhibitor. Our previous study showed that BBR may reverse the increase of disaccharidase activity induced by Stzid (Liu et al. 2008a,b). The inhibition of the $\boldsymbol{\alpha}$-glucosidase activity delayed the decomposition carbohydrate digestion and increased chyme accessing to the lower small intestine, where the most abundant population of endocrine L cells were located (Kreymann et al. 1987, Cani et al. 2007). The undigested carbohydrate possibly stimulated the GCG secretion at the lower segment of the gut through an osmotic action.

This study was focused on the effect of BBR on Stzidinduced diabetic rats. In other experimental models or normal rats, whether BBR may show similar effects need to be further investigated.

In conclusion, our results suggested that modulating GCG secretion may be one of the mechanisms of BBR antidiabetes effect. These findings highlight the systematical therapeutic potential of a poorly absorbed drug in the gut.

\section{Declaration of interest}

There is no conflict of interest for all the authors to the study.

\section{Funding}

The financial support for this research from the National Natural Science Foundation of China (No. 30873123) is gratefully acknowledged.

\section{Acknowledgements}

We thank Mark Geesey for valuable comments of the manuscript.

\section{References}

Anini Y, Hansotia T \& Brubaker PL 2002 Muscarinic receptors control postprandial release of glucagon-like peptide-1: in vivo and in vitro studies in rats. Endocrinology 143 2420-2426.

Cani PD, Daubioul CA, Reusens B, Remacle C, Catillon G \& Delzenne NM 2005 Involvement of endogenous glucagon-like peptide-1(7-36) amide on glycaemia-lowering effect of oligofructose in streptozotocin-treated rats. Journal of Endocrinology 185 457-465.

Cani PD, Hoste S, Guiot Y \& Delzenne NM 2007 Dietary non-digestible carbohydrates promote L-cell differentiation in the proximal colon of rats. British Journal of Nutrition 98 32-37.

Cheng Z, Pang T, Gu M, Gao AH, Xie CM, Li JY, Nan FJ \& Li J 2006 Berberine-stimulated glucose uptake in L6 myotubes involves both AMPK and p38 MAPK. Biochimica et Biophysica Acta 1760 1682-1689.

Doyle ME \& Egan JM 2007 Mechanisms of action of glucagon-like peptide 1 in the pancreas. Pharmacology and Therapeutics 113 546-593.

Drucker DJ 2003 Glucagon-like peptide-1 and the islet beta-cell: augmentation of cell proliferation and inhibition of apoptosis. Endocrinology 144 5145-5148. 
Fehmann HC, Goke R \& Goke B 1995 Cell and molecular biology of the incretin hormones glucagon-like peptide-I and glucose-dependent insulin releasing polypeptide. Endocrine Reviews 16 390-410.

Holst JJ \& Gromada J 2004 Role of incretin hormones in the regulation of insulin secretion in diabetic and nondiabetic humans. American Journal of Physiology. Endocrinology and Metabolism 287 E199-E206.

Holst JJ, Deacon CF, Vilsboll T, Krarup T \& Madsbad S 2008 Glucagon-like peptide-1, glucose homeostasis and diabetes. Trends in Molecular Medicine 14 $161-168$.

Iritani N, Sugimoto T, Fukuda H, Komiya M \& Ikeda H 1999 Oral triacylglycerols regulate plasma glucagon-like peptide-1(7-36) and insulin levels in normal and especially in obese rats. Journal of Nutrition 129 46-50.

Ko BS, Choi SB, Park SK, Jang JS, Kim YE \& Park S 2005 Insulin sensitizing and insulinotropic action of berberine from cortidis rhizoma. Biological and Pharmaceutical Bulletin 28 1431-1437.

Kong W, Wei J, Abidi P, Lin M, Inaba S, Li C, Wang Y, Wang Z, Si S, Pan H et al. 2004 Berberine is a novel cholesterol-lowering drug working through a unique mechanism distinct from statins. Nature Medicine 10 1344-1351.

Kreymann B, Williams G, Ghatei MA \& Bloom SR 1987 Glucagon-like peptide-1 7-36: a physiological incretin in man. Lancet 2 1300-1304.

Leng SH, Lu FE \& Xu LJ 2004 Therapeutic effects of berberine in impaired glucose tolerance rats and its influence on insulin secretion. Acta Pharmacologica Sinica 25 496-502.

Liu H, Liu X, Jia L, Liu Y, Yang H, Wang G \& Xie L 2008a Insulin therapy restores impaired function and expression of P-glycoprotein in blood-brain barrier of experimental diabetes. Biochemical Pharmacology 75 1649-1658.

Liu L, Deng Y, Yu S, Lu S, Xie L \& Liu X $2008 b$ Berberine attenuates intestinal disaccharidases in streptozotocin-induced diabetic rats. Die Pharmazie 63 384-388.

Lu T, Liang Y, Song J, Xie L, Wang GJ \& Liu XD 2006 Simultaneous determination of berberine and palmatine in rat plasma by HPLC-ESI-MS after oral administration of traditional Chinese medicinal preparation Huang-Lian-Jie-Du decoction and the pharmacokinetic application of the method. Journal of Pharmaceutical and Biomedical Analysis 40 1218-1224.

Meier JJ \& Nauck MA 2005 Glucagon-like peptide 1(GLP-1) in biology and pathology. Diabetes/Metabolism Research and Reviews 21 91-117.

Orskov C, Poulsen SS, Moller M \& Holst JJ 1996 Glucagon-like peptide I receptors in the subfornical organ and the area postrema are accessible to circulating glucagon-like peptide I. Diabetes 45 832-835.

Pan GY, Wang GJ, Liu XD, Fawcett JP \& Xie Y 2002 The involvement of P-glycoprotein in berberine absorption. Pharmacology \& Toxicology 91 193-197.

Pan GY, Wang GJ, Sun JG, Huang ZJ, Zhao XC \& Liu XD 2003 Inhibitory action of berberine on glucose absorption. Yao Xue Xue Bao 38 911-914.

Ritzel U, Fromme A, Ottleben M, Leonhardt U \& Ramadori G 1997 Release of glucagon-like peptide-1 (GLP-1) by carbohydrates in the perfused rat ileum. Acta Diabetologica 34 18-21.
Schmidtler J, Schepp W, Janczewska I, Weigert N, Furlinger C, Schusdziarra V \& Classen M 1991 GLP-1-(7-36) amide, -(1-37), and -(1-36) amide: potent cAMP-dependent stimuli of rat parietal cell function. American Journal of Physiology 260 940-950.

Tang LQ, Wei W, Chen LM \& Liu S 2006 Effects of berberine on diabetes induced by alloxan and a high-fat/high-cholesterol diet in rats. Journal of Ethnopharmacology 108 109-115.

Turner N, Li JY, Gosby A, To SW, Cheng Z \& Miyoshi H 2008 Berberine and its more biologically available derivative, dihydroberberine, inhibit mitochondrial respiratory complex I: a mechanism for the action of berberine to activate AMP-activated protein kinase and improve insulin action. Diabetes 57 1414-1418.

Turton MD, O'Shea D, Gunn I, Beak SA, Edwards CM, Meeran K, Choi SJ \& Bloom SR 1996 A role for glucagon-like peptide-1 in the central regulation of feeding. Nature 379 69-72.

Verdich C, Flint A, Gutzwiller JP, Naslund E, Beglinger C, Hellstrom PM \& Astrup A 2001 A meta-analysis of the effect of glucagon-like peptide-1 (7-36) amide on ad libitum energy intake in humans. Journal of Clinical Endocrinology and Metabolism 86 4382-4389.

Wang ZS, Lu FE, Chen G, Xu LJ \& Zou X 2007 Effect of berberine on insulin secretion and glucokinase activity of NIT-1 cells. Yao Хие Хие Bao 42 1045-1049.

Yi F, Sun J, Lim GE, Fantus IG, Brubaker PL \& Jin T 2008 Cross talk between the insulin and Wnt signaling pathways: evidence from intestinal endocrine L cells. Endocrinology 149 2341-2351.

Yin J, Gao Z, Liu D, Liu Z \& Ye J 2007 Berberine improves glucose metabolism through induction of glycolysis. American Journal of Physiology. Endocrinology and Metabolism 8 456-459.

Yu S, Pang XY, Deng YX, Liu L \& Liu XD 2007 A sensitive and specific liquid chromatography mass spectrometry method for simultaneous determination of berberine, palmatine, coptisine, epiberberine and jatrorrhizine from Coptidis rhizoma in rat plasma. International Journal of Mass Spectrometry 268 $30-37$.

Zhang MF \& Shen YQ 1989 Antidiarrheal and anti-inflammatory effects of berberine. Acta Pharmacologica sinica 10 174-176.

Zhou JY, Zhou SW, Zhang KB, Tang JL, Guang LX, Ying Y \& Li DD 2008 Chronic effects of berberine on blood, liver glucolipid metabolism and liver PPARs expression in diabetic hyperlipidemic rats. Biological \& Pharmaceutical Bulletin 31 1169-1176.

Received in final form 4 November 2008

Accepted 7 November 2008

Made available online as an Accepted Preprint 7 November 2008 